\title{
The Relationship between Iranian EFL Learners' Use and Preferences of Language Learning Strategies and Their Meta-Knowledge and Tasks of Pragmatic Competence
}

\author{
Khadijeh Najafi ${ }^{1}$, Firooz Sadighi ${ }^{1}$, Mohammad Sadegh Bagheri ${ }^{1} \&$ Lotfollah Yarmohammadi ${ }^{1}$ \\ ${ }^{1}$ Department of Foreign Languages, Shiraz Branch, Islamic Azad University, Shiraz, Iran \\ Correspondence: Firooz Sadighi, Department of Foreign Languages, Shiraz Branch, Islamic Azad University, \\ Shiraz, Iran. E-mail: firoozsadighi@yahoo.com
}

Received: September 17, 2016 Accepted: October 8, 2016 Online Published: January 12, 2017

doi:10.5539/ijel.v7n1p142 URL: http://dx.doi.org/10.5539/ijel.v7n1p142

\begin{abstract}
The present study investigated the relationship between Iranian EFL learners' use and preferences of language learning strategies and their meta-knowledge and the tasks of pragmatic competence. Quick Oxford Placement Test, version 2 (2004) was administered and 120 upper-intermediate EFL university students majoring in English translation and TEFL were recruited from the available branches of the Islamic Azad University, Fars province. Likewise, a questionnaire entitled Iranian EFL learners' meta-knowledge and pragmatic tasks (2016) was used to explore EFL learners' meta-knowledge and tasks of pragmatic competence and the mean score was calculated. Then, Oxford Strategy Inventory for Language Learning (1990) was used to analyze EFL learners' use and preferences of language learning strategies and the mean score was calculated. Also, to examine any possible relationship between EFL learners' use and preferences of language learning strategies and their meta-knowledge and pragmatic tasks, some correlations were run. The results of data analyses showed that Iranian EFL learners were moderate in meta-knowledge and tasks of pragmatic competence and in their use of language learning strategies in general. More detailed analyses of the data ranked the order of the applications of the strategies as: social strategies, meta-cognitive strategies, cognitive strategies, memory strategies, compensation strategies and affective strategies from the most to the least frequent strategies applied by the participants of the study. There was a significant medium positive relationship between meta-knowledge and tasks of pragmatic competence and meta-cognitive strategy. However, there were slight but significant positive relationships between meta-knowledge and tasks of pragmatic competence and compensation and affective strategies and no relationships between meta-knowledge and tasks of pragmatic competence and social, affective and compensation strategies.
\end{abstract}

Keywords: language learning strategies, EFL learners, strategy use, meta-knowledge, tasks, pragmatic competence

\section{Introduction}

Actually, knowledge of language is not only acquiring linguistic knowledge, rather learners need to know how to apply their linguistic knowledge in different contexts. According to Austin (1962), language is used as a tool to perform actions and accordingly in his Speech Act theory, he attempts to describe how people are able to perform the function of an utterance other than simply the literal meaning. Learners need to communicate effectively in social interactions and this is in line with the concept of communicative competence that Hymes (1972) introduced. He argued that a learner should also pay attention to the social and cultural factors that affect the L2 learning in order to be able to communicative effectively. In order to acquire communicative competence well, paying attention to the components of communicative competence is of high importance. One of the significant components of communicative competence is pragmatic competence. Actually without pragmatic competence, language competence is incomplete.

Bachman \& Palmer stated "pragmatic knowledge enables us to create or interpret discourse by relating utterances or sentences and texts to their meanings, to the intentions of language users, and to relevant characteristics of the language use setting," they also specified "pragmatic knowledge enables us to create or interpret discourse by relating utterances or sentences and texts to their meanings, to the intentions of language 
users, and to relevant characteristics of the language use setting"(2010, p. 46).

Ji (2008), as depicted in Figure 1, classified pragmatic knowledge into general pragmatic information, metalanguage information, meta-pragmatic information, speech acts, cultural knowledge, pragmatically oriented tasks, as well as knowledge regarding how to learn pragmatic knowledge.

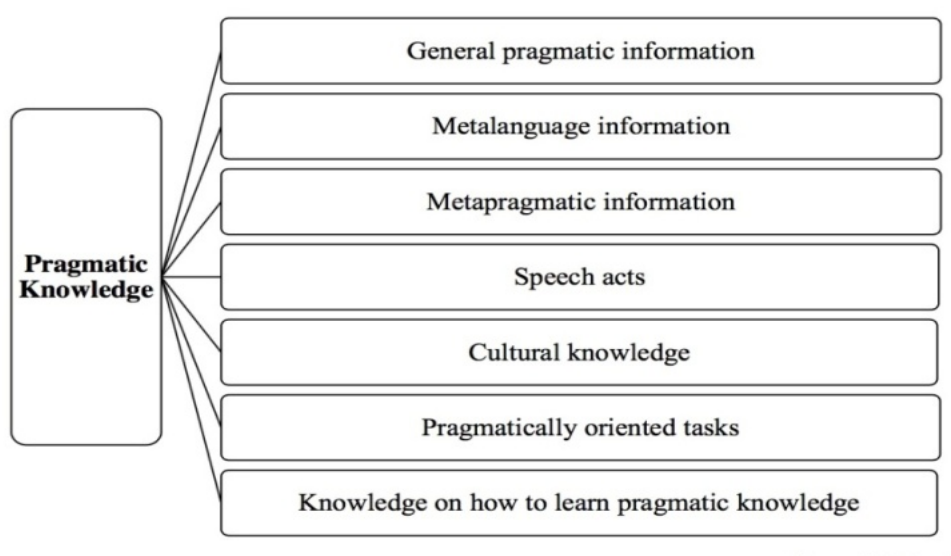

Figure 1. Classification of pragmatic knowledge

In the present study, meta-knowledge and tasks of pragmatic competence including meta-language information, meta-pragmatic information, knowledge of speech acts and pragmatically oriented tasks were investigated. Meta-language information, according to Richards, Schmidt, Platt \& Schmidt (2002) refers to the type of language that can be used to describe languages. Metapragmatic information defines language that portrays or describes the pragmatic function of some speech acts (Silverstein, 2001). And the knowledge of Speech acts, according to Ji (2008), concentrates on the detailed and meta-pragmatic descriptions of speech acts.

Actually, based on the previous studies (e.g., Hou, 2007; Rose, 2009; Schauer, 2006; Bardovi-Harlig \& Dörnyei, 1998), little attention is given to the study of pragmatics and EFL learners with different proficiency levels face difficulties in pragmatic comprehension. Even learners with high linguistic proficiency levels do not acquire the necessary pragmatic proficiency and this shows that little attention is given to the study of pragmatics. Also in university contexts, most EFL learners even those whose majors are English do not attain sufficient pragmatic proficiency although they are linguistically proficient. Actually, issues related to pragmatic competence are rarely considered in university setting and the teaching and learning processes in this regard are seldom taken into account. Furthermore, the focus of most studies in regard with pragmatic competence is on the teaching processes and the learning processes are mostly ignored. The present study shifts from teachers and teaching methods towards learners and learning techniques and eventually demonstrates the need for essential changes in the curriculum.

In fact, when studies concentrate more on language learning, the strategies and techniques that learners employ to learn the second or foreign language come to the center of attention. In the present study, from among the techniques L2 learners frequently employ, language-learning strategies are the focus of attention. Once the techniques and strategies of efficient language learners are recognized, teachers better know to select the appropriate materials and teach in regard with the real needs of the learners. Furthermore, being familiar with the characteristics, techniques, and strategies that learners use facilitates language-learning process for both teachers and learners. In addition, with this knowledge and awareness, learners' L2 learning process can be enhanced through learners training by their teachers.

The strategies that L2 learners employ in the process of learning the target language have been categorized by many professional experts in the area of foreign/second language learning. However, in the present research, Oxford's (1990) taxonomy of language learning strategies is applied.

Overall, the present study aims at investigating the relationship between meta-knowledge and tasks of pragmatic competence of EFL learners who are upper-intermediate regarding their level of language proficiency and their use and preferences of language learning strategies. The findings of this study fill the gap between research on teaching and learning, and provide valuable data for the development of pragmatic knowledge in EFL university 
learners.

\section{Review of Literature}

As already mentioned in the previous section, pragmatic competence is an essential component of language learning that can be developed with sufficient linguistic input encompassing enough features of the target language (Bialystok, 1993). There are a number of studies that highlight the significance of pragmatic competence in general and pragmatic competence development of language learners in particular. Some of the major studies related to this study will be discussed below.

Hou (2007) carried out a study to investigate the pragmatic competence development of Chinese College English learners and the implications of these levels of proficiency for pragmatic English teaching. Based on the findings of the study, it was concluded that pragmatic failures would generate misinterpretations, and even extreme feelings or emotions (e.g., prejudice, predisposition and resentment) in cross-cultural communication as communication failures or difficulties to agreeable interpersonal relationships may arise through such misinterpretations. Further, the researcher argues if the goal of language learning is to communicate effectively in the cross-cultural settings, it is essential to identify and reduce College English learners' pragmatic failures and to efficiently develop their pragmatic competence.

Another study, which observed EFL learners' pragmatic competence development, was conducted by Rose (2009) in Hong Kong. This study provided evidence of EFL learners' considerable pragma-linguistic development. All learners made frequent use of the popular, conventionally indirect, request strategy, which was an indication that they had moved past earlier pre-basic and formulaic stages. The study also revealed that learners had made little progress in the development of socio-pragmatics, particularly in EFL settings as they used more alerters in hearer-dominant circumstances and the use of supportive moves remained at a relatively low level. The study found that language learners had huge pragma-linguistics development but lacked socio-pragmatic development, particularly in EFL settings.

Schauer (2006) carried out a similar study to examine the development of learners' pragmatic competence during their stay in the L2 target setting. The pragmatic development of ESL learners was investigated in two aspects namely, pragmatic awareness and productive pragmatic competence. The ESL learners' pragmatic competence indicated that a sojourn in the L2 setting improved the competency of learners' pragmatic awareness. In order to achieve pragmatic competence, the study revealed that there was a need to combine learners' pragmatic competence with contextual, personal and temporal elements. Compared with many other studies conducted in this field, this study indicated the close connection between EFL learners' pragmatic awareness and their pragmatic development, and explored the process of learners' pragmatic competence.

In the area of language learning strategies in ESL/EFL contexts, a number of studies specify that learning strategies play an important role in successful language learning.

Gan, Humphreys, \& Hamp-Lyons (2004) reported a comparative study of successful and unsuccessful EFL learners. The findings indicated that unsuccessful learners employed rote- memorization, while the successful learners use a systematic strategy and supplemented rote learning with strategies for boosting what they had already learned.

Halbach (2000) came up with a similar finding after analyzing the use of language learning strategies of EFL learners. She recognized that the unsuccessful learners lacked critical self-awareness; they rarely employed the monitoring and self-evaluation strategies in the process of L2 learning.

In another study, Takeuchi (2003) recognized the characteristics of Japanese successful language learners via their biographies. Finally, Griffiths (2008) investigated good language learners with regard to such individual different factors such as motivation, age, personality, and attitude.

Taken together, the studies performed on language learning strategies (e.g., Gan, Humphreys, \& Hamp-Lyons, 2004; Halbach, 2000; Takeuchi, 2003, Griffiths, 2008, etc.) specified a successful language learner as one who is a mentally active learner, monitors the process of language comprehension and production, provides opportunities to practice communication in the target language, uses background linguistic and general knowledge, employs different memorization techniques, and asks questions for information and clarification.

Nevertheless, little attention has been paid to learning objectives of L2 learners. These objectives probably vary by general purpose in language learning including the need for survival communication skills, an official requirement in school or academic study, passing tests, travelling to another country. Consequently, the setting of learning together with language learners' objectives, according to Cohen (1990), specify the types of learning events engaged in and thus the types of learning strategies that can be expected to best help language learning. 
Due to the fact that language learners use different types of strategies, they may consider priority over some strategies compared with others.

Rahimi, Riazi, \& Saif (2008) examined the language strategy use of 196 Iranian EFL learners at a post-secondary level to specify what features and factors can affect learners' use of strategies. The results of a strategy questionnaire and attitude inventories indicated that motivation was the main predictor of EFL learners' use of strategies; yet, gender was found to have no role in forming strategies employed by learners.

In another attempt, Hajhashemi, Ghombavani, \& Amirkhiz (2011) investigated the relationship between multiple intelligences and the strategy of Iranian high school EFL learners. The participants included two hundred and twenty-nine students who responded to McKenzie's (1999) multiple intelligence inventory and the Strategy Inventory for Language Learning (SILL). The findings revealed positive correlation between MI profiles and language learning strategies use among the EFL learners. The findings also displayed that meta-cognitive strategies and social strategies had the highest frequency use.

Similarly, Nikoopour, Farsani, \& Neishabouri (2011) studied the strategies used by Iranian EFL learners. Strategy Inventory for Language Learning (SILL) was adopted for data collection. The findings of their study showed moderate use of language-learning strategies by EFL learners. Among the strategies they frequently adopted, metacognitive strategies were the most frequent and memory strategies were found to be the least.

Salehi \& Bagheri (2011) also took the issue into account by investigating the relationship between learning styles and strategies of EFL learners. Two questionnaires and think aloud protocols were adopted to examine this relationship among 110 Elementary level EFL learners. They concluded that between the group learning styles and the metacognitive strategies, the kinesthetic styles and the cognitive, the auditory styles and metacognitive and social strategies, and the compensation strategies, the visual styles and memory strategies meaningful relationships were observed.

In sum, a plethora of research on pragmatics in ESL/EFL learning has specified the necessity to assist language learners develop pragmatic awareness and capability with education in pragmatics in order to attain pragmatic competence. Findings of the above-mentioned studies provide rich evidence to support the need for language learners to develop pragmatic competence, yet further studies need to be carried out in different settings, with diverse samples to get a deeper insight into how language learners can develop such competency successfully and effectively. It is also worth examining strategy-instruction for developing pragmatics as research (Mendelsohn, 1998) has indicated that strategy-based instruction is beneficial for language learners to develop macro skills of speaking, listening, reading and writing.

\section{Methodology}

\subsection{Participants}

The participants of the present study were originally 178 male and female Iranian EFL undergraduate and graduate university students majoring in TEFL and English translation at the Islamic Azad University, Kazeroun, Fasa, Lar, Marvdasht, \& Sepidan branches, Fars province. These students participated in a standard test of English proficiency, i.e., Quick Oxford Placement Test (QPT) version two and overall 120 upper- intermediate students were selected based on their scores on the test. Meanwhile, they were at an average range of 27 years old.

\subsection{Instrumentation}

In order to collect the related data, the following instruments were used.

\subsubsection{Quick Oxford Placement Test (QPT), Version 2}

In the present study, Quick Oxford Placement Test (QPT), the paper and pen (P\&P) version was administered in order to assign the learners into upper-intermediate level of language proficiency and homogenize the participants. The test consists of two parts. The typical reliabilities according to Geranpayeh (2003) were close to 0.9 for the 60 item test and 0.85 for the 40 item test.

\subsubsection{The Questionnaire on EFL Learners' Meta-Knowledge and Tasks of Pragmatic Competence}

Actually, it seems that there has not been any instrument to date to investigate meta-knowledge and tasks of pragmatic competence. Hence, the present questionnaire (see Appendix A) was designed based on Ji's (2008) classification of pragmatic knowledge. As it was mentioned before, Ji (2008) classified pragmatic knowledge into general pragmatic information, cultural knowledge, knowledge of how to learn pragmatic knowledge, met-language information, meta-pragmatic information and pragmatically oriented tasks (knowledge of speech acts) and in the present research meta-knowledge and tasks of pragmatic competence were examined. 
The questionnaire consisted of three sections. The first section in this part (Qs 1-8) aimed at investigating the participants' meta-pragmatic information (knowledge of speech acts). Questions 1 and 2 focused on the speech act of apology; questions 3 and 4 concentrated on the speech act of request. In questions 5 and 6 , the speech acts of compliment were presented and questions 7 and 8 focused on the speech acts of thanking. The next section focused on meta-language information (Qs 9 and 10) and the last two questions (Qs 11 and 12) concentrated on pragmatically oriented tasks.

As it is shown in Table 1, the questions were selected from previous studies and arranged by the researchers of the study.

Table 1. Distribution of the questionnaire items and their sources

\begin{tabular}{ll}
\hline Questions & Sources \\
\hline $1,2,3,4,7$ & Birjandi, \&Rezaei (2010) \\
$5,6,8$ & Kia and Salehi (2013) \\
9,10 & collection of TEFL PhD entrance exam (pp.42-45) \\
11,12 & Yuan, 2012 \\
\hline
\end{tabular}

The questions were not translated into Farsi due to the difference in language and culture between Farsi and English and the possibility that a fully accurate translation might not occur. The Questionnaire took about 10 minutes for the students to complete.

To provide a valid test, based on the suggestions provided by subject matter experts different parts of the questionnaire were adopted from previous studies. To make sure about the validity of the final manuscript, the developed version was given to the same experts. The final manuscript for piloting included twelve items. The reliability estimate which was estimated via Chronbach's Alpha was $(\alpha=0.6)$. However, in order to increase the internal consistency of the questionnaire, the researcher went through item analysis to identify if there were items with very low reliability estimates. Having recognized one item with low reliability estimate, reliability estimate equals $(\alpha=0.7)$.

\subsubsection{Oxford (1990) Strategy Inventory for Language Learning (SILL)}

The most inclusive taxonomy of language learning strategies and the most widely employed strategy scale has been proposed by Oxford (1990). Oxford developed the SILL to measure language learning strategies for ESL and EFL learners (Version 7.0). This test took about 30 minutes for the students to complete. The SILL consists of 50 items in the two dichotomous constructs of direct and indirect learning strategies, which is shown in Table 2.

Table 2. Oxford (1990) Strategy Inventory for Language Learning (SILL)

\begin{tabular}{lll}
\hline Direct strategies & Memory & 9 item \\
29 items & Cognitive & 14 items \\
& Compensation & 6 items \\
\hline Indirect strategies & Metacognitive & 9 items \\
21 items & Affective & 6 items \\
& Social & 6 items \\
\hline
\end{tabular}

In administering the SILL, respondents were asked to reflect on their use of language learning strategies in five-point Likert-scale items from "(1) never or almost never true of me" to "(5) always or almost always true of me." This questionnaire has been widely checked for its reliability and validity in multiple ways (Oxford, 1996). For example, Oxford \& Nyikos (1993) found Cronbach's Alpha of 0.96 for SILL. Oxford and Burry-Stock (1995) established its predictive criterion-related validity using its correlative relationship with language performance measures like course grades and proficiency ratings.

\subsection{Data Collection Procedure}

As the first step in data collection, 178 Iranian male and female graduate and undergraduate EFL university students majoring in English translation and TEFL were randomly selected from among available branches of the Islamic Azad University, Kazeroun, Fasa, Lar, Marvdasht and Sepidan, Fars province. These 178 students took part in a test of language proficiency, Quick Oxford Placement Test (QPT) in order to be homogenized and based 
on their scores on the test. Finally, 120 upper-intermediate students were recruited for the study. One week later, these 120 participants were requested to answer the questions of the Oxford (1990) Strategy Inventory for Language Learning (SILL) as well as the Questionnaire on EFL learners' meta-knowledge and tasks of pragmatic competence. Having collected the completed questionnaires, the researchers analyzed the results.

\section{Results}

In what follows, the results of the analyses of the data will be presented.

\subsection{EFL Learners' Meta-Knowledge and Tasks}

In order to investigate EFL learners' meta-knowledge and tasks of pragmatic competence, the participants' answers to the Questionnaire on EFL learners' meta-knowledge and tasks of pragmatic competence are tabulated and analyzed below.

Table 3. Mean scores of the participants' meta-knowledge and tasks

\begin{tabular}{llllllll}
\hline Valid 120 & Mean & Median & Mode & SD & Variance & Minimum & Maximum \\
\cline { 2 - 7 } Missing 0 & 6.2917 & 6.0000 & 6.00 & 2.2986 & 5.284 & .00 & 10.00 \\
\hline
\end{tabular}

Since the items of the questionnaire included one correct answer and two distracters for each item, based on the views of the experts in the field, each correct response was given one point and no negative point was assigned to the wrong responses. Then, the total score for each student was calculated. According to Table 2, the mean score in this part was about $6.29(\mathrm{M}=6.29)$. Due to the fact that this part included 12 items, the estimated mean of the population should be 6 . According to the tabulated data, the mean score in this part is about 6.29 . By comparing the estimated mean of the population which should be 6 to the mean score obtained in this part which is 6.29 , it is evident that the mean score is very near to the estimated mean of the population. We can conclude that the participants of the study were overall moderate concerning meta-knowledge and tasks of pragmatic competence.

\subsection{EFL Learners' Use and Preferences of Language Learning Strategies}

In order to analyze the use of language learning strategies by EFL learners in general, the mean score was calculated. According to the criteria of mean (Oxford, 1990), a mean score equal or above 3.50 was interpreted as strong strategy users, $(3.50 \leq \mathrm{M} \leq 5.00=$ strong); a mean score equal or above 2.50 , but below 3.50 was interpreted as moderate strategy users $(2.50 \leq \mathrm{M}<3.50=$ moderate $)$, and a mean score below 2.50 was considered as weak strategy users $(\mathrm{M}<2.50=$ weak). Table 3 reports the mean score of the participants in SILL in general.

Table 4. Mean score of the participants' scores in SILL

\begin{tabular}{|c|c|c|c|c|c|c|c|}
\hline Valid & Mean & Median & Mode & SD & Variance & Minimum & Maximum \\
\hline 120 & 3.3185 & 3.4259 & $.00^{\mathrm{a}}$ & .70724 & 500 & .00 & 4.46 \\
\hline
\end{tabular}

Considering Table 3, the mean score is about $3.31(\mathrm{M}=3.31)$. Concerning the criteria of Oxford (1990) mentioned above $(2.50 \leq \mathrm{M}<3.50=$ moderate $)$, the participants of the study were on the whole moderate in using language learning strategies.

In order to have a detailed analysis of the data in regard with different parts of SILL, the mean scores of the participants in different parts of SILL are reported in Table 4.

Table 5. Hierarchy of the mean score of the participants' parts of SILL

\begin{tabular}{llllllllll}
\hline \multicolumn{2}{c}{$\mathrm{N}$} & & & & & & & \\
& Valid & Missing & Mean & Median & Mode & SD & Variance & Minimum & Maximum \\
\hline Social & 120 & 0 & 3.65 & 3.75 & 3.33 & 1.03 & 1.07 & .00 & 5.00 \\
Meta-cognitive & 120 & 0 & 3.59 & 3.83 & 4.00 & .91 & .84 & .00 & 4.78 \\
Cognitive & 120 & 0 & 3.58 & 3.71 & 3.21 & .81 & .65 & .00 & 4.71 \\
Memory & 120 & 0 & 3.35 & 3.44 & $3.33^{\mathrm{a}}$ & .80 & .64 & .00 & 5.00 \\
Compensation & 120 & 0 & 2.94 & 3.00 & 2.67 & 1.01 & 1.03 & .00 & 5.00 \\
Affective & 120 & 0 & 2.77 & 3.00 & 3.00 & .88 & .78 & .00 & 4.83 \\
\hline
\end{tabular}


The reports of the participants' performance in different parts of the SILL according to Table 5 are as follows:

Social strategy with the mean score of 3.65 ranked as the most frequent strategy applied by the participants of the study; meta-cognitive strategy with the mean score 3.59 ranked as the second frequent applicable strategy by the participants; while, cognitive strategy with the mean score 3.58 ranked as the third frequent applicable strategy. In Sum, according to the criteria of Oxford (1990), the participants of the study were strong in the use of social, cognitive and meta-cognitive strategies. Meanwhile, memory strategy with the mean score of 3.35 ranked the fourth frequent strategy, while compensation strategy with the mean score of 2.94 and affective strategy with the mean score of 2.77 ranked as the least frequent strategies respectively.

\subsection{The Relationship between EFL Learners' Meta-Knowledge and Tasks of Pragmatic Competence and Their Preferences in Language Learning Strategies}

In order to investigate the relationship between EFL learners' meta-knowledge and tasks of pragmatic competence and their preferences in language learning strategies, some correlations between different parts of SILL and meta-knowledge and tasks of pragmatic competence were run and the results are tabulated in Table 5.

Table 6. Correlations between EFL learners' meta-knowledge and tasks of pragmatic competence and their preferences in language learning strategies

\begin{tabular}{|c|c|c|c|c|c|c|c|c|c|}
\hline & & & $\begin{array}{l}\text { Meta-knowledge } \\
\text { and tasks }\end{array}$ & $\begin{array}{l}\text { Social } \\
\text { strategy }\end{array}$ & $\begin{array}{l}\text { Meta-cognitive } \\
\text { strategy }\end{array}$ & $\begin{array}{l}\text { Cognitive } \\
\text { strategy }\end{array}$ & $\begin{array}{l}\text { Memory } \\
\text { strategy }\end{array}$ & $\begin{array}{l}\text { Compensation } \\
\text { strategy }\end{array}$ & $\begin{array}{l}\text { Affective } \\
\text { strategy }\end{array}$ \\
\hline \multirow[t]{3}{*}{$\begin{array}{l}\text { Spearman's } \\
\text { rho }\end{array}$} & \multirow[t]{3}{*}{$\begin{array}{l}\text { Meta-knowledge } \\
\text { and tasks }\end{array}$} & $\begin{array}{l}\text { Correlation } \\
\text { Coefficient }\end{array}$ & 1 & .06 & $.31^{* *}$ & .11 & -.04 & $.23^{*}$ & $.25^{* *}$ \\
\hline & & Sig. (2-tailed) & . & .50 & .00 & .22 & .65 & .01 & .00 \\
\hline & & $\mathrm{N}$ & 120 & 120 & 120 & 120 & 120 & 120 & 120 \\
\hline
\end{tabular}

According to the above tabulated data, the relationship between the participants' meta-knowledge and tasks of pragmatic competence and six different language strategies were investigated using Spearman's rho and the following results were obtained.

According to Cohen (1988), the interpretation of data relating to $\mathrm{r}$ value is as follows: " $\mathrm{r}=.1$ to .29 small correlation; $\mathrm{r}=.3$ to .49 medium correlation and $\mathrm{r}=.5$ to 1 strong correlation" (pp. 79-81). Accordingly, there were not any significant relationships between meta-knowledge and tasks of pragmatic and social, cognitive as well as memory strategies since $p>0.05$. However, there were significant small relationships between meta-knowledge and tasks of pragmatic competence and compensation and affective strategies and a medium correlation between meta-knowledge and tasks of pragmatic competence and meta-cognitive strategy.

\section{Discussion and Conclusion}

Based on the analyses of the related data which were presented before, it was found that Iranian EFL university students were in general moderate in their meta-knowledge and tasks of pragmatic competence, including meta-language information, meta-pragmatic information, knowledge of speech acts and pragmatically oriented tasks.

Moreover, Iranian EFL learners were in general moderate strategy users in their language learning. The result of this part is in line with Nikoopour, Farsani, \& Neishabouri (2011) who studied the strategies used by Iranian EFL learners. The findings of their study indicated moderate use of language-learning strategies by EFL learners.

Furthermore, EFL learners in this study applied social strategy as the most frequent language learning strategy. This part of the study is in contrast with Yilmaz (2010) who indicated that the EFL learners employed compensation strategies, as their preferred language learning strategy. Besides, there was not any significant relationship between meta-knowledge and tasks of pragmatic and social strategies as the preferred language learning strategies by our Iranian EFL learners. Social strategies facilitate the process of language learning via interactions with other people. According to Oxford (1990), language is a form of social behavior and learning any language includes other people, and it is extremely significant that L2 learners employ proper social strategies in this process. These strategies fall into three classes, namely asking questions for information or clarification, cooperation, and empathy with other individuals.

Also, there was a medium correlation between meta-knowledge and tasks of pragmatic competence and 
meta-cognitive strategy as the second frequent strategy used by EFL learners. Metacognitive strategies assist L2 learners to control their own cognition and include over- viewing and linking with material already learnt, paying attention, focusing on speech production and comprehension, organizing materials, setting objectives and, planning for a language event, seeking practice opportunities and self-assessment (Oxford,1990).

Likewise, there was not any significant relationship between meta-knowledge and tasks of pragmatic competence and cognitive strategies as the third applicable strategies employed by EFL learners. Cognitive strategies involve conscious ways of dealing with the target language and fall into four classes, namely practicing, receiving and sending messages, analyzing and reasoning, and creating structure for input and output.

Also, there was not any significant relationship between Iranian EFL learners meta-knowledge and tasks of pragmatic competence and memory strategies as the fourth applied strategies. Memory strategies according to Oxford (1990) involve the mental processes required for storing and retrieving new information. They include four sets, namely creating mental linkages, applying images and sounds, reviewing well, and employing action.

Additionally, there was a slight significant relationship between meta-knowledge and tasks of pragmatic competence and compensation strategies as the fifth applicable strategies. Compensation strategies enable learners, despite gaps in knowledge, to exploit the language either in speaking or writing to properly convey the meaning. They fall into two classes, namely guessing intelligently and overcoming limitations in speaking and writing. These strategies are employed by L2 learners when confronted with a temporary gap in speaking or writing (Oxford, 1990).

Finally, the least frequent applicable strategies were affective strategies. The results of this part of the study confirmed Y1lmaz's (2010), Nikoopour et al.'s (2011) and Hong-Nam \& Leavell's (2006) who reported affective strategies as the least frequent learning strategies. Additionally, there was a significant relationship between meta-knowledge and tasks of pragmatic competence and affective strategies, though slight. Affective strategies help L2 learners to manage their feelings and motivation as well as attitudes related to language learning. These goals can be attained through self-encouragement, controlling emotional temperature and lowering anxiety (Oxford, 1990).

Overall, acquiring pragmatic competence is an indispensable part of EFL learning. According to Ji (2008), pragmatic competence and linguistic competence can progress side by side. Considering the findings of the present study, language teachers can be assured that in order for the learners to communicate in an acceptable way, the importance of acquiring pragmatic competence cannot be neglected. In fact, by concentrating more on language learning, the strategies and techniques that learners employ to learn the second or foreign language come to the center of attention. In the present study, from among the techniques L2 learners frequently employ, language-learning strategies are the focus of attention. Once the techniques and strategies of efficient language learners are recognized, teachers better know how to select the appropriate materials and teach based on the real needs of the learners. Furthermore, being familiar with the characteristics, techniques, and strategies that learners use facilitates language-learning process for both teachers and learners. In addition, with this knowledge and awareness, learners' L2 learning process can be enhanced through learners' training by their teachers.

\section{References}

Austin, J. (1962). How to do things with words. Oxford: Oxford University Press.

Bachman, L. F., \& Palmer, A. S. (2010). Language assessment in practice: Developing language assessments and justifying their use in the real world. Oxford, UK: Oxford University Press.

Bardovi-Harlig, K., \& Dörnyei, Z. (1998). Do language learners recognize pragmatic violations? Pragmatic versus grammatical awareness in instructed L2 learning. TESOL Quarterly, 32, 233-262. https://doi.org/10.2307/3587583

Bialystok, E. (1993). Symbolic representation and attentional control in pragmatic competence. In G. Kasper \& S. Blum-Kulka (Eds.), Interlanguage Pragmatics (pp. 43-57). Oxford: Oxford University Press.

Birjandi, P., \& Rezaei, S. (2010). Developing a multiple-choice discourse completion test of interlanguage pragmatics for Iranian EFL learners. ILI Language Teaching Journal (Special Issue: Proceedings of the First Conference on ELT in the Islamic World), 6(1,2), 43-58.

Cohen, A. (1990). Language learning: Insights for learners, teachers, and researchers. New York. Newbury House.

Gan, Z., Humphreys, G., \& Hamp-Lyons. (2004). Understanding successful and unsuccessful EFL Students in $\begin{array}{lllll}\text { Chinese universities. The Modern Language Journal, } & \text { 229-244. }\end{array}$ 
https://doi.org/10.1111/j.0026-7902.2004.00227.x

Geranpayeh, A. (2003). A quick review of the English Quick Placement Test. Research Notes. 8-10. University of Cambridge, Cambridge.

Griffiths, C. (2008). Lessons from good language learners. Cambridge: Cambridge University Press. https://doi.org/10.1017/CBO9780511497667

Hajhashemi, K., Ghombavani, F., \& Amirkhiz, Y. (2011). The relationship between Iranian EFL high school students' multiple intelligence scores and their use of learning strategies. English Language Teaching, 4(3), 214-222. https://doi.org/10.5539/elt.v4n3p214

Hou, T. (2007). A survey on pragmatic competence development of Chinese English learners and implications for pragmatic English teaching. Unpublished M.A. thesis. Taiyuan: Taiyuan Technology University.

Hymes, D. (1972). On communicative competence. In J. B. Pride \& J. Holmes (Eds.), Sociolinguistic (pp. 269-285). Harmondsworth: Penguin.

Ji, P. (2008). Pragmatics and pedagogy in college English teaching. Shanghai: Shanghai Foreign Language Education Press.

Kia, E., \& Salehi, M. (2013). The effect of explicit and implicit instruction of English thanking and complimenting formulae on the developing pragmatic competence of Iranian EFL learners. Journal of Basic and Applied Scientific Research, 3(8), 202-215.

Mckenzie, W. (1999). Multiple intelligences survey [Electronic version]. Retrieved from http://surfaquarium.com/MI/MI Invent.Htm

Mendelsohn, D. J. (1998). Teaching listening. Annual Review of Applied Linguistics, 18, 81-98. https://doi.org/10.1017/S0267190500003494

Nikoopour, J., Farsani, M. A., \& Neishabouri, J. K. (2011). Language learning strategy preferences of Iranian EFL students. IPEDR, 5, 356-360.

Oxford, R. L. (1990). Language learning strategies: What every teacher should know. New York: Newbury House/Harper \& Row.

Oxford, R. L. (Ed.). (1996). Language learning strategies around the world: Cross-cultural perspectives. Honolulu: University of Hawaii Press.

Oxford, R. L., \& Burry-Stock, J. A. (1995). Assessing the use of language learning strategies worldwide with the $\mathrm{ESL} / \mathrm{EFL}$ version of the Strategy Inventory for Language Learning. System, 23(2), 153-175. https://doi.org/10.1016/0346-251x(94)00047-a

Oxford, R. L., \& Nyikos, M. (1989). Variables affecting choice of language learning strategies by university students. Modern Language Journal, 73, 291-300. https://doi.org/10.1111/j.1540-4781.1989.tb06367.x

Rahimi, M., Riazi, A., \& Saif, S. (2008). An investigation into the factors affecting the use of language learning strategies by Persian EFL learners. CJAL, 11(2), 31-60.

Richards, J., Schmidt, R., Platt, H., \& Schmidt, M. (2002). Longman dictionary of language teaching and applied linguistics. London: Longman.

Rose, K. R. (2009). Interlanguage pragmatic development in Hong Kong, phase 2. Journal of Pragmatics, 41(11), 2345-2364. https://doi.org/10.1016/j.pragma.2009.04.002

Salehi, M., \& Bagheri, M. S. (2011). Relationship between Reid's learning styles and Oxford's language: The learning strategies in adult EFL learners of Iran Language Institute. Iranian EFL Journal, 7(4), 120-142.

Schauer, G. A. (2006). The development of ESL learners' pragmatic competence: A longitudinal investigation of awareness and production. In K. Bardovi-Harlig, C. Félix-Brasdefer, \& A. S. Omar (Eds.), Pragmatics language learning (vol. 11, pp. 135-164). Honolulu: University of Hawaii Press.

Silverstein, M. (2001). The limits of awareness. In A. Duranti (Ed.), Linguistic anthropology: A Reader (pp. 382-401). Malden: Blackwell.

Takahashi, S. (1990). Pragmatic transferability.Studies in Second Language Acquisition, 18, 189-223. https://doi.org/10.1017/S0272263100014881

The Research Center of Toofan Institute. (2009). Ganjine Azmoonhaye Vorudi Doctora-Reshte Amoozesh Zaban [A collection of TEFL PhD entrance Exam] (pp.42-45). Emamat Publication, Mashhad, Iran. 


\section{Appendix A}

\section{The Questionnaire on Iranian EFL Learners' Meta-Knowledge and Pragmatic Tasks}

Instructions: The present questionnaire is a part of a research project on perception of pragmatics by Iranian EFL university students as well as their pragmatic knowledge. To this end, we would like you to help us by completing this questionnaire. The questionnaire included two parts. The first part consisted of 8 Likert type questions and the second part included 12 multiple choice questions. We are interested in your views. Your answers to the questions will be kept confidential and will be only used for academic purposes. Thank you very much for your assistance.

\section{Demographic Information:}

Name: Gender: Age:

Major: University:

\section{Matapragmatic information, knowledge of speech acts}

1. Suppose you are late for an important class and the teacher is very punctual and principled. How would you express your apology in this situation?

The Teacher: This is the third time you're late for this class. Next time I won't let you in.

You.

a. I understand. I won't be late again.

b. Sorry but the important thing is that I attend, right?

c. Things happen in life, sorry.

2. You are almost asleep in the class while the teacher is teaching. The teacher gets very angry when he sees you sleeping in the class. How do you express your apology?

The Teacher: Did you sleep well last night?

You.

a. I'm sorry; I will try and not let it happen again.

b. I'm sorry, but I didn't sleep a wink last night.

c. Pardon me. I couldn't help it.

3. Suppose you have got 14 on your reading test and you are sure that your score could have been higher. How would you ask your teacher to check your paper again?

a. I know that I did better than 14 . You could have made a mistake when you were grading.

b. I studied really hard for this test and I thought that I would do better than 14. Is there any way that you could review my test and double check my grade?

c. You need to recheck my test. I don't think that I got a 14 on this test.

4. Suppose you need a recommendation letter for teaching at an English language institute very urgently for tomorrow. How would you ask your teacher to do that?

a. Can you write me a recommendation letter? And I need it by tomorrow.

b. I wonder if you could possibly give me a recommendation letter for my workplace.

c. Could you please write me a letter of recommendation really quickly? The deadline is tomorrow and it's really important!

5. You run into one of your friends at a party. She/he is wearing a nice, new outfit. How would you compliment her/him?

a. What's happening? Your outfit is very beautiful.

b. You are looking very nice today. Did you get some new clothes?

c. This model is built for you. It goes on very well with you. 
6. You come across your friend on campus. This is the first time you see him in his new glasses. How would you compliment him?

a. Nice glasses, they look really good on you.

b. Your new glasses are perfect. I like them. How much did you pay for them?

c. Oh boy! I hadn't seen you with such cute face. You appear to be Einstein's brother

7. While you are studying in the dormitory, your friend is listening to loud music. The music distracts you. You request your friend to turn it down and he does so immediately. How would you thank him?

a. Thanks for understanding, I really appreciate it.

b. Thank you. You did me a favor.

c. Oh, cheers. That was intolerable

8. You are in a rush to get to University. Suddenly you fall down and hurt your leg. A passerby helps you get up. How would you thank him/her?

a. Thanks a lot. I hope you won't get hurt. God bless you.

b. It was really nice of you to stop and help me, I really appreciate it. Thank you so much.

c. I'm so sorry. Thanks a lot. I'm so indebted to you

\section{Meta-language information}

9. The relationship between soul and spirit is the same as the relationship between which of the following words with intellect.
a. brain
b. chest
c. will

10. The relationship between $\underline{B u d}$ and blossom is the same the relationship between caterpillar and ........
a. larva
b. leaf
c. butterfly

\section{Pragmatically oriented tasks}

11. Tom is buying a ticket at the booking office of a Theme park.

Tom: I'd like to buy one ticket and I want to have a map of the Theme park.

Ticket seller: All right. What's your post code?

Question: What does the ticket seller mean?

a. The ticket seller wants to book Tom's address.

b. The ticket seller wants to have Tom's post code.

c. The ticket seller wants to know the language Tom uses.

12. Jack, a villain, met one acquaintance, Richard, on the corridor in a hospital.

Jack: I am going to have a new heart.

Richard (contemptuously): It is about the time.

Question: What does Richard imply?

a. Jack has a serious heart disease and needs a new heart.

b. Jack has become a good man.

c. Jack needs to realize his evil and totally change his behavior

\section{Copyrights}

Copyright for this article is retained by the author(s), with first publication rights granted to the journal.

This is an open-access article distributed under the terms and conditions of the Creative Commons Attribution license (http://creativecommons.org/licenses/by/4.0/). 